\title{
Entitlement, Justification, and the Bootstrapping Problem
}

\author{
Jon Altschul \\ Loyola University- New Orleans \\ Published 2012 in Acta Analytica, Vol. 27, no. 4: 345-366
}

\begin{abstract}
According to the bootstraping problem, any view that allows for basic knowledge (knowledge obtained from a reliable source prior to one's knowing that that source is reliable) is forced to accept that one can utilize a track-record argument to acquire justification for believing that one's belief source is reliable; yet, we tend to think that acquiring justification in this way is too easy. In this paper I argue, first, that those who respond to the bootstrapping problem by denying basic knowledge succumb to over-intellectualizing epistemology, and secondly, reliabilist views avoid over-intellectualization only at the expense of sanctioning bootstrapping as a benign procedure. Both of these outcomes are difficult to bear. To ward off each of these unsavory outcomes, I propose an alternative solution that draws on a distinction between two separate epistemic concepts: entitlement and justification.
\end{abstract}

Reliabilists endorse the following claim: S's belief that $p$ is justified if and only if S's belief was produced by $\mathrm{G}$, where $\mathrm{G}$ is a reliable source of information. In recent years the bootstrapping problem—presented independently by Richard Fumerton (1995), Jonathan Vogel (2000), and Steward Cohen (2002) - has been offered as a devastating objection to reliabilism. ${ }^{1}$ To illustrate the problem, suppose that Reggie has a highly reliable perceptual system. Having never before thought about whether his system is reliable, he crafts the following track-record argument: ${ }^{2}$

$\mathrm{B} 1$. There is an $\mathrm{F} a$ ahead (based on an occurrent perceptual experience) B2. My current experience represents $a$ as being F (via introspection) B3. So, on this occasion my perceptual experience is accurate

After conducting numerous similar procedures of the (B1-B3) sort, Reggie infers:

\footnotetext{
${ }^{1}$ The target view attacked by the three authors mentioned here is reliabilism about knowledge. In this paper I shall follow several writers (Zalabardo, 2005; Vogel, 2008; Kallestrup, 2009) by concentrating on justification or warrant, rather than knowledge.

${ }^{2}$ Track-record arguments were first discussed in Alston (1996).
} 
B4. My perceptual experience is accurate on most occasions

B5. Therefore, my perceptual system is a reliable source of information

If reliabilism is true, then Reggie should be justified in holding B5. ${ }^{3}$ B1 and B2 are justified, given that perception and introspection are reliable, and each subsequently formed belief within the track-record argument is produced by a reliable process: B3 is deduced from B1 and B2, B4 is the result of induction from the conjunction of numerous B3-like beliefs, and B5 is deduced from B4. The trouble is that the track-record argument enables Reggie to bootstrap his way to the conclusion, yet many would agree that this is an inadequate way of acquiring justification of this sort. The reliabilist has somehow gone off-course, because it makes it too easy to acquire justification for our higher-order beliefs about the reliability of our own belief sources.

Two popular stances have emerged as reactions to the bootstrapping problem. According to first, bootstrapping one's way to a belief about a belief source's reliability involves epistemically circular reasoning, which is impermissible. The only way to preclude such reasoning is to impose as a necessary condition on having justification to rely on one's source that one already have justification to believe that that source is reliable. According to the second stance, there exists no such necessary condition on justification for the beliefs a source produces; consequently, those who react this way typically view bootstrapping as a benign procedure.

\footnotetext{
${ }^{3}$ Epistemologists sometimes emphasize the distinction between one's having justification for a belief and one's being justified in holding a belief. I will gloss over this distinction and use the expressions interchangeably. For the purposes of this paper, I will understand having justification, or warrant, as follows: When $r$ is a justification (warrant) one has to believe that $p$, were one to believe that $p$ on the basis of $r$, one would be justified (warranted) in holding $r$. The precise nature of the "basis relation" between a justification (warrant) and corresponding belief has proven difficult to characterize (Cf. Audi, 1993); because the primary topic of this paper does not depend on any particular conception of a belief's being "based on" something else, I will not pursue this issue any further.
} 
In Section I of this paper, I claim that both of these stances toward the bootstrapping problem are unacceptable. Against the first stance, instituting such a strict requirement on our ordinary perceptually based beliefs and memory based beliefs imposes an overintellectualized epistemology; intuitively, such beliefs are epistemically secured even for those individuals who lack justification for thinking the source of those beliefs are reliable. Against the second stance, sanctioning bootstrapping as legitimate seems too high a cost for warding off other alternatives.

The project of this paper is to propose a solution to the bootstrapping problem that avoids adopting either of these two unsavory stances. Central to my solution is a distinction between two types of epistemic goods: entitlement and justification. In Section II, I introduce the distinction according to which, following the work of Tyler Burge, entitlement is a more primitive type of epistemic warrant that applies to our various non-inferential beliefs. Justification is a more complex type that applies to beliefs that are inferred from other beliefs. Justified beliefs, as opposed to entitled beliefs, are those that are grounded by cognitively accessible reasons. Entitlement is weaker than justification in the sense that the standards for having an entitlement to a belief are less demanding than they are for justification. The crux of this paper is Section III where I argue that the reason bootstrapping is impermissible is that the warrant for B1 and B2 fails to transmit across the inference to B3. Furthermore, that the track-record argument engenders a failure of warrant transmission can be rationalized by the proposed distinction between entitlement and justification. Finally in Section IV, I conclude with a discussion on why this proposal does not force us to reject epistemic closure. 


\section{Section I: Two Responses to the Bootstrapping Problem}

To begin it is worth noting that the bootstrapping problem is not just a problem for reliabilism. In fact, it has been argued that the problem plagues any theory that allows for the existence of what Cohen (2002, p. 310) calls basic knowledge: knowledge obtained from a source prior to one's knowing that that source is reliable. If having knowledge implies having justification, then anyone who allows for basic knowledge should also allow for basic justification: justification to believe a proposition without already having justification to believe that the source of that belief is reliable. ${ }^{4}$ Certain evidentialist views, for example, allow that a perceptual belief is justified simply by virtue of the believer enjoying an appropriate perceptual experience. The evidentialist holds, just as the reliabilist does, that one is justified in taking one's experience at face value without already being justified in believing that one's experiences are reliable. ${ }^{5}$ An evidentialist would therefore seem to be equally as permissive as a reliabilist to allow that B1 and B2 are justified beliefs, which in turn provide Reggie with justification for holding B3. This being the case, the procedure that takes Reggie from the conjunction of his B3-like beliefs to B4 would have to be viewed as an epistemically permissible chain of reasoning by the evidentialist. Thus, the bootstrapping problem emerges once again. So, it turns out that bootstrapping is not specifically a problem for reliabilism. For, if it is strong

\footnotetext{
4 The term 'already' here signifies epistemic priority, rather than temporal priority. Thus, following Pryor (2000, p. 525), one has justification for belief B without already having justification for belief B* just in case one's justification for B does not rest or depend on one's justification for B*. I assume that epistemic priority is an asymmetric relation, such that the justification for $\mathrm{B}$ is prior to the justification for $\mathrm{B}^{*}$ only if the justification for $\mathrm{B}^{*}$ is not prior to the justification for $\mathrm{B}$.

${ }^{5}$ Conee and Feldman (2001), Pryor (2000), Pritchard (forthcoming)
} 
enough to undermine the theory, it is strong enough to undermine many other theories as well. ${ }^{6}$

One way to prohibit bootstrapping, then, would be to deny the possibility of basic justification. This move would be especially appealing to the philosopher who holds that the concept of justification centers on the idea of being receptive to the reasons one has and using them to shape one's doxastic livelihood. Justification, understood here, is the mark of an achievement on the subject's part— to believe as one ought implies that the subject has fared well or has done a good job in the face of her epistemic situation. This line of thought is, I believe, congruent with Wilfrid Sellars' views in epistemology, who famously said that "[i]n characterizing an episode or a state as that of knowing...we are placing it in the logical space of reasons, of justifying and being able to justify what one says." (1963, p. 169) As rational epistemic agents, we have the ability to engage ourselves in critical, deliberative reasoning, and in doing so we come to evaluate our reasons_decide whether they are compelling or not. "What is my reason for thinking this?" we can ask. "Is $r$ a good enough reason for me to believe that $p$ ?" That we can be reflective of our reasons has epistemological significance. For a belief to gain membership in the Sellarsian space of reasons, it must be the case that the subject recognizes, or is at least in a position to recognize, that there are other beliefs within the space that provide logical support.

Before elaborating further on this conception of justification, it is worth noting that those who disallow basic justification naturally tend toward coherentist or holistic

\footnotetext{
${ }^{6}$ Vogel (2008), however, has recently argued that bootstrapping is impermissible by internalist's lights. Vogel characterizes internalism as the view that knowledge requires justification, and justification requires evidence (p. 520). As I interpret Vogel, internalism about knowledge implies evidentialism about justification.
} 
positions. (Cf. Sellars 1963 and Cohen 2002). Davidson (1986) is a prime example. He holds that only a belief can justify another belief, because he thinks that there needs to exist an appropriate logical relation between a reason and the belief that the reason is a reason for. Davidson is not entirely specific on what he means by a "logical relation." However, he does seem to hold that a requisite on something's counting as a reason, and falling in a logical relation to a belief, is that the content of the reason have the same sort of structure as the content of the associated belief: propositional structure. Perhaps what Davidson had in mind is that a logical relation between two mental states consists in each of their contents being such that they can appear as a premise or a conclusion in a logically valid argument. ${ }^{7}$ But it is only propositions that can appear in an argument. Moreover, as Davidson assumes, experience lacks propositional structure. Others since Davidson have gone on to argue that perception has a fundamentally different kind of content from a belief's content, namely nonpropositional content. ${ }^{8}$ Thus, since beliefs are the only sorts of mental states that have the requisite propositional structure, only beliefs can count as reasons.

The Davidsonian position runs contrary to the commonly held view is that quite often a perceptual experience can by itself cause a corresponding belief, which thereby amounts to knowledge of the world. Thus, the coherentist has traditionally faced objection on the grounds that it cannot explain how perceptually based beliefs can—independent of any supplementary supporting beliefs—constitute perceptual knowledge. It is not my aim to offer a general critique of coherentism. Doing so would

\footnotetext{
${ }^{7}$ For further discussion on Davidsonian epistemology, see Pryor (2005) and Brueckner (2008).

8 Evans 1982; Peacock 2001; Burge 2003; Heck 2000 \& 2007; Bermudez 2007; Roskies 2008
} 
go well beyond the scope of this paper. Instead, I wish to pursue an alternative view that purports to avoid this shortcoming.

Turning back to the view we now considering, the suggestion would be that for any given belief $\mathrm{B}^{*}$, one has justification for $\mathrm{B}^{*}$ only if one has other beliefs whose contents could be cited as premises in an argument that has the content of $\mathrm{B}^{*}$ as its conclusion. It is the subject's own epistemic responsibility to determine whether such an argument is forceful; if it is not, or if the requisite argument is altogether absent, she would be obliged from the standpoint of justification to eradicate her belief. As it relates to our present discussion on bootstrapping, these considerations would naturally lead one to abandon the notion of basic justification. For according to this view, if it is right that B1 is justified, Reggie must already be in possession of some auxiliary beliefs that serve as reasons supporting it. Presumably, the set of reasons supporting B1 would include B5. Furthermore, if the justification for B5 is epistemically prior to the justification for B1, and also epistemic priority is understood in terms of asymmetric dependence (see fn. 4), then B1 cannot be justified unless B5 is already justified.

In light of its promise for warding off the bootstrapping problem, to think of justification along these lines carries with it an unbearably high cost. Those who adopt this stance are guilty of over-intellectualizing epistemology, for it demands of subjects that they possess highly sophisticated self-reflective abilities which certain individuals may lack. If justification requires that subjects always have reflective access to the features that make them justified, it would seem that many of people's beliefs are unjustified; moreover, on the assumption that knowing implies being justified, we would be forced to conclude that these people lack knowledge. But, this conclusion flies in the 
face of common intuition. A young child, for example, has perceptual knowledge that there is a red cube ahead (when she sees one there) yet she is unable to reflect on any reason she supposedly has for that belief. Indeed, her intellectual faculties may be sufficiently undeveloped that she is simply unable to form higher-order judgments about whether her experience is accurate or her perceptual system is reliable. It would seem that it is the fact alone, and not the antecedent knowledge of the fact, that the child's perceptual system is reliable which enables her experience to confer knowledge.

Reliabilists are able to accept this last claim. Indeed the urgency of avoiding overintellectualization has served as one of reliabilism's chief attractions. ${ }^{9}$ But as we have seen, reliabilism faces the bootstrapping problem. Let us now consider one frequently discussed reliabilist response that has been put forth.

We should first note that although many agree that there is something wrong with Reggie's chain of reasoning, it is not immediately clear exactly what is wrong. After all, each step is supported by either deductive or inductively strong inferences, and all of his beliefs have been reliably produced. As a general truth, deductive or inductive reasoning to a conclusion is a perfectly permissible procedure, from an epistemic standpoint. Assuming one makes a deductive or inductively strong inference on the basis of a justified belief, one acquires a new justification for the belief one has inferred. This is to say that the justification transmits from the basing belief(s) to the inferred belief. Consider an example. Suppose that Detective Johnson's belief that Smith's fingerprints were on the murder weapon justifies Johnson in believing that Smith is the murderer. That he is so justified makes him justified in believing that Brown is not the murderer

\footnotetext{
${ }^{9}$ Cf. Goldman (1979)
} 
(when he deduces the latter proposition from the prior one). By inferring a proposition on the basis of an already-held belief, Johnson acquires a new justification for holding that inferred belief. It is in this sense that we suppose Johnson's justification transmits across the inferences he makes.

One might suggest that the answer to the question, "What is wrong with Reggie's chain of reasoning?" is, "Not a thing." Some philosophers, for instance, such as James Van Cleve (2002) and Michael Bergmann (2004, 2006), have argued that justification transmits even in cases where the subject makes use of bootstrapping, as with Reggie's track-record argument. According to this response to the bootstrapping problem, the suggestion is that pulling oneself up by one's own bootstraps can be a perfectly permissible form of reasoning. ${ }^{10}$ This response is especially appealing if we consider the following closure principle on justification, which few philosophers would wish to deny:

(CPJ) If $\mathrm{S}$ is justified in believing that $p$, and $\mathrm{S}$ knows that $p$ logically implies $q$, and $\mathrm{S}$ deduces $q$ on the basis of $p$, then $\mathrm{S}$ is justified in believing that $q$.

Let $p$ stand for the conjunction of the contents of B1 and B2, and let $q$ stand for the content of B3. Given CPJ and the procedure undertaken by Reggie, it follows that B3 is justified. Let us assume that the induction from the conjunction of B3-like beliefs to B4 is sufficiently strong to justify B4. If we then let $p$ stand for the content of B4 and $q$

\footnotetext{
${ }^{10}$ Bergmann's $(2004 ; 2006$, Ch. 7) claim is that the reason why we tend to have such an unsettling reaction toward track-record arguments is that we often fail to distinguish between the epistemic success of following such arguments from its dialectical efficacy—where the former falls within an "unquestioned context" and the latter a "questioned context." (2004, p. 718) While it may be that track-record arguments are ill-equipped to change the mind of one who is uncertain of the reliability of a source, this does not speak to the question of whether one may utilize a track-record argument to acquire justification for thinking that that source is reliable. See Vogel (2008, appendix) for an argument against Bergmann's proposal.
} 
stand for the content of B5, it follows from CPJ that B5 is justified. ${ }^{11}$ But, if it is true that B5 is justified, what then is the source its justification? Proponents of this response, like Van Cleve or Bergmann, would claim that the justification for B5 could only arise from the chain of reasoning that begins with B1 and B2. For, how else could it be that one obtains justification for the belief that one's perceptual system is reliable? If this is the only way to explain how B5 could be justified, and we assume CPJ, the only way to accommodate these claims—other than embracing skepticism—is to allow that justification transmits even in cases of bootstrapping.

I find this sort of response to the bootstrapping problem leaving me extremely unsettled. It strikes me as obvious that Reggie has behaved somehow irrationally or irresponsibly when he concludes his track-record argument by forming B5. It is reasonable to think that the sorts of appropriate, epistemically-supporting reasons or evidence for a belief about the reliability of one's own experiences would be information that is independent of - or at least in addition to - the contents of those very experiences, such as the testimony of one's optometrist or neurologist or philosophical advisor.

\footnotetext{
${ }^{11}$ It is controversial whether the relation between B4 and B5 is deductive rather than inductive. The answer hinges on how best to understand the concept of reliability. On a rather crude interpretation, reliable processes are those that are, as a matter of fact, generally accurate on most occasions. On such an interpretation, B4 would logically imply B5. Others, however, claim that reliability is a modal concept, such that a reliable process is one that yields mostly true beliefs in a range of nearby possible worlds (Vogel, 2008, p. 521). On this interpretation, B5 would not deductively follow from B4, and moreover one would be unable to appeal to CPJ to establish that B5 is a justified belief. Indeed, Vogel (2008, Section IV) capitalizes on this modal component to stop what he calls a "rollback" of undoing of justifications in the track-record argument. Specifically, Vogel's claim is that whereas Reggie is justified (or knows, in keeping with Vogel's terminology) in holding B4, he would not be justified in holding B5. Because B4 does not logically imply B5 (as Vogel assumes), Vogel is able to maintain this position without standing in violation of closure. Of course, even if a deductive closure principle is unbroken here, it seems that Vogel still would be forced to reject the following plausible-sounding, albeit stronger, principle: "If S is justified in believing that $p$, and $\mathrm{S}$ knows that $p$ strongly inductively implies $q$, and $\mathrm{S}$ inductively infers $q$ on the basis of $p$, then $\mathrm{S}$ is justified in believing that $q$." As it will turn out, there is little concerning what I say in later sections that hinges on how we understand the relation between B4 and B5. Therefore, I will proceed along the assumption that the relation is deductive.
} 
Obtaining this sort of evidence requires investigation that goes beyond mere introspection and logical deduction. We tend to think that were Reggie a responsible agent, he would have made the recognition somewhere along his deliberations that his procedure is illsuited to justify him in believing that his perceptions are reliable. If Van Cleve or Bergmann are willing to forfeit all of these powerful intuitions just for the sake of safeguarding against skepticism, I fail to see why skepticism is any less tolerable.

\section{Section II: Entitlement and Justification}

The considerations of the previous section suggest that we should be in search of a view that allows for the existence of basic knowledge, but that also prohibits bootstrapping as viable mode of reasoning. In this section I will propose a view that, as we will see in Section III, is equipped to make the needed accommodations. But, before I explain how this might work, let me first cautiously suggest that the trouble we have faced so far in trying to respond to the bootstrapping problem can be attributed to some of the unresolved issues at play in the internalism and externalism debate in epistemology. The first response we saw is internalist in the sense that justified belief is conceived as being grounded by good reasons, reasons that are recognizable to the subject upon reflection. ${ }^{12}$ On this conception, internalists have the advantage of prohibiting bootstrapping, but only at the expense of denying the existence of basic knowledge, and moreover succumbing to

\footnotetext{
12 The kind of internalism I have in mind should be understood as what Conee and Feldman (2001) call accessibilism. This is to be contrasted with mentalism, according to which the justificational status of a subject's beliefs is determined by non-factive mental states, such as beliefs and experiences, and by relations between them. The views I am exploring in this paper are not meant to challenge mentalism. Mentalism, but not accessibilism, has been defended against reliabilism on the grounds that our mental twins in skeptical scenarios are massively unreliable, yet they are no less justified in their beliefs as we are. For a defense of reliabilism against this charge, see Altschul (Forthcoming).
} 
over-intellectualization. Externalist views, in contrast, such as reliabilism, have the advantage of allowing for basic knowledge, but only at the expense of sanctioning bootstrapping as viable. I propose that we can do better than either of these options, and to do so we should take seriously the idea that a tenable epistemology contains both internalist and externalist elements.

Let us begin by introducing the concept of warrant. Warrant is to be understood as the most basic type of epistemic good that, when combined with true belief, constitutes knowledge in most cases. Not all cases, however, because Gettier counterexamples are applicable to warranted true belief. Our concept of warrant must therefore be distinguished from the one espoused by Alvin Plantinga (1993), who conceives of warrant as that property which takes true belief to knowledge. According to Plantinga, all instances of warranted true belief are also instances of knowledge.

Following the recommendation of Tyler Burge $(1993,2003)$, I propose that warrant is divided into two sub-types: entitlement and justification. Entitlement is a more primitive type of warrant that applies to our various non-inferential beliefs, where belief based on perception serves as the paradigm. ${ }^{13}$ Justification is a more complex type of warrant that applies to beliefs that are inferred from other beliefs. As will prove crucial later on, one of the key distinctions between these two epistemic concepts is that whereas entitlement is externalist, in the sense that it is warrant that need not be fully conceptually accessible to the warranted subject, justification is internalist in that it is warrant by reason that is

\footnotetext{
${ }^{13}$ As I say, perceptual belief is the paradigmatic class of non-inferential belief to which we possess entitlements. There is a further question as to which type of warrant gets attached to other belief classes. Do we, for instance, have entitlements to our memorial beliefs, testimonial beliefs (Cf. Burge, 1993), $a$ priori beliefs (Cf. Peacock, 2004, Ch. 6), beliefs about our own mental states (Cf. Burge, 1996)? This is both an interesting and important question, but providing an answer goes beyond the scope of this work. For our purposes, we will focus our attention specifically on perceptual entitlement.
} 
conceptually accessible on reflection to the warranted subject. ${ }^{14}$ I will begin by highlighting some of the important features that go in to explaining Burgean perceptual entitlement.

The driving force behind this view is that the perceptual system is a representational system with its own characteristic function, which is to veridically represent the organism's normal environment. ${ }^{15}$ That the system has this function makes an indispensable contribution to the subject's fulfilling her aim of believing truthfully. For Burge, absent reasons for doubt, one has an entitlement to rely on one's perceptual experience in belief formation (i.e. to believe there is an $\mathrm{F} a$ over there on the basis of perceptually representing an $a$ as being F) ${ }^{16}$ given that two conditions are satisfied. First, the perceptual content is anti-individualistically individuated. According to perceptual anti-individualism how the perceptual system represents the world is partially determined by various causal-formative interactions, which have occurred throughout the development of the system, between features in the environment and the system itself. That the perceptual system has the capacity to represent $a$ as being F could be explained,

${ }^{14}$ Burge (2003), p. 504-5.

15 For Burge, the "normal environment" is not to be understood as the actual environment or the environment in which the organism usually resides, nor — as Goldman (1986) describes—as an environment that is relevantly similar to the actual world. Rather, it is the environment that determines the perceptual representational capacities of the organism. (Burge, 2005, p. 4) For more on how the normal environment is characterized, see Majors and Sawyer (2005).

${ }^{16}$ To say that a perceptual state represents $a$ as being $\mathrm{F}$ does not imply that the content is composed of concepts (e.g. the concept of an $a$ and the concept of $F$-ness). Indeed, Burge holds that perception has nonpropositional content, given that nonlinguistic animals, lacking conceptual abilities, as well as humans are capable of perceptual representation. (Cf. Burge, 2003, Section II and p. 525) According to Burge's theory of perception, a perceptual content contains two separate, nonconceptual abilities (see his 2005, Section II). The first is a general, repeatable ability to represent various types of objects and properties by way of exhibiting a sensitivity to various features in the environment (which Burge calls a pattern-based representation). The second component of a perceptual content involves an occurrence-based representational ability to apply the pattern-based representation to a singular, context-dependent element that makes demonstrative reference to a particular. This understanding of perceptual content has relevant parallels to Burge's (1977) characterization of a de re belief. 
for example, by the fact through the subject's lifetime, it came into causal contact with

Fa's present in the environment. ${ }^{17}$

Such a history of causal interaction, as a minimal requirement on content

individuation, is vital to the perceptual system's capacity to represent the world because it helps establish conditions for veridicality, conditions for success. The perceptual system

is a success-oriented system. It is in the business of getting things right. Given a set of

distal and proximal stimulation, the system will perform either properly or improperly.

Even when it gets things wrong, as occurs, say, when one views an illusion, this can only

be explained in connection to some standard for getting things right. ${ }^{18}$ This is all to say

that the perceptual system has a characteristic function, and it can successfully or

unsuccessfully carry out that function. ${ }^{19}$ What the system has the function to do in a

${ }^{17}$ According to Burge (2007, p. 203; 2003, p. 511; 2005, Section I) there are alternative explanations, consistent with perceptual anti-individualism, that can determine the individuation of a given perceptual state. First, the subject's representation can be a composite of percepts (e.g. $a$ and F) the possessions of which are explained by her interactions with the referent of those percepts in isolation of the other (e.g. she has confronted $a$ 's that were not $\mathrm{F}$, like $\mathrm{G} a$ 's, and F-ness that did not belong to $a$ 's, like $\mathrm{F} b$ 's and $\mathrm{F} c$ 's). Secondly, the individuation of a state can be explained completely independently of the subject's own personal history. It could be that the subject never interacted with Fa's (nor with $a$ 's nor with F-ness), but past members of the species of which the subject is herself a member have. A harmless distal stimulus may trigger a (inaccurate) predatory alert representation in a creature, yet the relevant content-individuating predators posed threats only to her ancestors, and died out well before the creature was born. This ability would be a trait passed down through the generations within the species. Finally, it could be that neither the subject nor her ancestors has ever confronted instances associated with a given representation-type at all. For example, I may (accurately or inaccurately) represent a shade of color with which I (or my ancestors) have never interacted. This last point does not undermine the claim that content individuation requires at least some successful interactions. Representing a never-before-seen color is possible only on the background condition that successful interactions have occurred between the perceptual system and instances within the more general category of property to which that never-before-seen color belongs. The relevant content-individuating properties out in the environment with which the perceptual system interacts need not be those which get represented, though commonly they are.

${ }^{18}$ Burge (2005), p. 5 \& 13-14

${ }^{19}$ According to Burge, the nature of the perceptual system's function is explained from both a philosophical and psychological perspective. On the one hand, he takes "it as obvious that it is known $a$ priori that the central representational function of a perceptual system is to perceive. This function is apriori associated with a representational function (to represent veridically)." (2003, p. 508) On the other hand, he thinks " $[\mathrm{t}] \mathrm{he}$ aim of the psychology of vision is to explain how the perceptual system normally gets things (approximately) right." (2005, p. 14) The job of psychologists is to uncover the general 
given situation is partially determined by the objects, properties, and relations in the environment with which it has interacted in the past. Such interactions help establish the principles that govern the formation of its perceptual states. ${ }^{20}$

The second condition that must be met for an experience to award an entitlement to a subject is that the content-individuating interactions have a sufficiently high degree of success. ${ }^{21}$ I understand 'success' in the following way: for a state that is already fully representational, the perceptual system's being in that state is caused by an instance of that which it represents. In its evolutionary developmental stage, before the perceptual system is sophisticated enough to generate full-blown experiences with representational contents, a successful interaction may be realized by the system's being in some nonrepresentational state, such that its being in that state is caused by an instance of that which—when it later on acquires a representational function—comes to be represented. When the individuation of a type of perceptual state is realized in this way, that state type is reliably veridical in the normal environment.

Satisfaction of the two above-described conditions is sufficient for a perceptual state to award the subject an entitlement to believe the world to be as her experience represents it as being. Absent reason for doubt, there is nothing beyond the having of the perceptual experience that is required to enjoy warrant. While the experience the subject enjoys is in

principles governing the perceptual system, which explains how it is able to veridically represent the world. (2005, Section III)

20 The account as I have described it is, admittedly, a rather simplified one. To characterize all of the complexities surrounding Burge's views on perceptual anti-individualism would go well beyond what can be accomplished here. For more on how Burge draws the connection between anti-individualism and the function of the perceptual system, see his (2003; 2005; and 2007, Introduction)

21 Burge (2003), p. 532 
fact a reliable indicator what is occurring in her surroundings, the subject need not know, or even be capable of thinking, that this is the case.

In contrast with the concept of entitlement, justification is a separate type of warrant that is backed by reasons. ${ }^{22}$ Reasons are equipped to rationally ground inferential beliefs because reasons, having the kind of propositional structure that can appear as premises in a possible argument, are such that they can face self-scrutiny by the subject. The justified subject has the standing obligation and responsibility to engage in such scrutiny of her reasons, depending on her epistemic situation. Thus, justified subjects must meet intellectualist requirements. To elaborate on what I mean by this, epistemologists should not ignore the Davidsonian stance, which was mentioned in Section I. As a matter on the structure of justification, I think it is right that the justificational, epistemic support a reason lends to a belief is of the very same kind as the logical support a premise lends to a conclusion in a valid argument. What is common to both kinds of support-relations is that the support consists in the fact that (or, in the logical case, at the least implies that) a belief (conclusion) can be inferred by one on the basis of a reason (premise). Hence, it is my contention that justification is that type of epistemic good that is underwritten by inferential epistemic support-justificational relations between reasons and beliefs consist in inferential relations.

To enjoy justification, it is not merely that such an argument be in place. In addition, insofar as a belief is held for the subject's own reasons, it is expected that she be in a position to appreciate the force of this argument, to decide for herself whether reasoning

\footnotetext{
${ }^{22}$ Whereas I have tried to offer a strict interpretation of Burge's views on perceptual entitlement, the account of justification I am describing here is not necessarily Burge's own, though it is inspired by some of the remarks he makes in his (2003).
} 
in this way is persuasive or not. The constraints on justification demand that the subject be willing to rationally scrutinize the relation between her reasons for belief and the belief itself. $^{23}$

Let me pause for one important clarification. The point I am making is that when a belief is grounded by a reason, or reasons, it elevated into the Sellarsian "logical space of reasons," the space of "...justifying and being able to justify what one says." This quote from Sellars implicitly suggests that justification is tied to the activity, not only of justifying one's own belief, but also of articulating one's justification in language. This latter point about language is perhaps too strong. The exercise of linguistically articulating one's justification is something in which most of us rarely partake, and yet many of our ordinary inferential beliefs are adequately justified. Most epistemologists today would agree that actively articulating one's reasons is too strong of a requirement on justification. Instead, the view of justification we are now considering places great weight on one's capacity to justify one's belief. But even on this more muted intellectualist requirement, believing for a reason implies that the reason is recognizable to the subject as her reason for belief. ${ }^{24}$

Burge breaks away from the time-honored assumption that knowledge implies being justified. For on his view, knowledge is warranted true belief (with the exception of Gettier-style situations). When one has an entitlement to one's perceptual belief (and it is true), this belief will constitute knowledge even if one lacks justification for holding it.

\footnotetext{
23 One philosopher whose epistemological views subscribe to this constraint on justification is John McDowell, who says: "Active empirical thinking takes place under a standing obligation to reflect about the credentials of the putatively rational linkages that govern it. There must be a standing willingness to refashion concepts and conceptions if that is what reflection recommends." (1994, p. 12-13)

${ }^{24}$ Cf. Brewer (1999), p. 18-20 and p. 164-166. Brewer calls this constraint justification the recognition requirement.
} 
But because one can enjoy a perceptual entitlement without already knowing that perception is a reliable source of information, it is consistent with Burge's view that there can be basic knowledge. Thus, over-intellectualization is averted.

It may still be asked: what explains why a subject's entitlement to rely on her experience in belief formation is specifically an epistemic kind of warrant? Put a slightly different way, one worry might be that if experience by itself is suited to confer perceptual knowledge, implying that the subject need not have access to that warrant, how can it be ensured that the transition between an experience and corresponding perceptual belief is specifically normative - such that it is rational for the subject to form the belief-as opposed merely brutely causal $?^{25}$ Some have argued that there simply is no such acceptable explanation and that the only way to resolve the matter is to assert that experiences are states with propositional contents; these contents would constitute reasons which are fit to be reflectively scrutinized by the subject. ${ }^{26}$

I claim that perceptual experiences provide warrant for belief, but they do not provide reasons. If it is right that the content of perception is nonpropositional, then it is not of the kind of mental state whose contents can stand as premises in a logically valid argument (see the discussion on Davidson in Section I). ${ }^{27}$ Perceptual beliefs, however, are propositional attitudes that do provide reasons for other beliefs. This, I argue,

\footnotetext{
25 This sort of worry has been raised against the reliabilist, as illustrated by Laurence Bonjour's (1980) character Norman, a reliable clairvoyant who has no reason for thinking that he has clairvoyant powers.

${ }^{26}$ Cf. McDowell (1994) and Brewer (1999)

27 Some nonconceptualists hold that all aspects of perception are nonpropositional (Evans, 1982), while there are others who hold that perceptual states contain varying levels of complexity associated with their contents, some levels of which are nonpropositionally structured and others are propositionally structured (Peacocke, 1992, Ch. 3). It is not vital that we settle on any specific view about the structure of perceptual content. Instead, our interests on this topic surround whether or not perceptual contents are fit to count as conceptually scrutinizable reasons, in the way that the Davidsonian demands. The point I am making is that they do not.
} 
supplies us with a basis for alleviating the above-stated worry. Let us look closely at an example. Suppose that on the basis of an occurrent visual experience, Peterson comes to believe that her surrounding environment is completely dark. This is a non-inferentially based, perceptual belief to which she is entitled. This perceptual belief (with the propositional content there is complete darkness all around) in turn provides Peterson with a reason (perhaps together with certain other beliefs, such as that she is now indoors) to believe that all the lights are off. Whenever a perceptual belief provides a reason to infer some proposition, the newly inferred belief comes under the jurisdiction of justification. For, the moment we engage in reasoning or make an inference, we have entered into the Sellarsian space of reasons. Entrance into the space demands that one be able to reflect on the epistemic strength of the supportive reasons. Thus, given that it was derived through inference, Peterson's belief that all the lights are off is subject to heightened epistemic standards — the standards of justification.

Notice what has transpired in this example. A non-inferential belief to which one has an entitlement makes an epistemic contribution to an inferential belief which one is thereby justified in holding. Although the non-inferential, perceptual belief lies outside the space of reasons (as it is itself non-reason based), it is nonetheless evident that it is offering rational support to one of the space's members. That being the case, a perceptual belief-insofar as it provides reason-based, inferential support to beliefs which are themselves members of the space of reasons - must itself be something one rationally holds onto.

The standards for entitlement are weaker than they are for justification. Noninferential, perceptual beliefs are not—as a necessary condition for warrant—subject to 
self-scrutiny, for entitlement has no such requirement. Nonetheless, because the perceptual beliefs to which we have entitlements bear a tight affiliation with the members of the space of reasons, as the example above illustrates, I suggest that other reasons within that space can affect the epistemic standing of those perceptual beliefs positioned outside the space. This provides us with our answer to the question of how it is that our non-inferential, perceptual beliefs are rationally held: they are susceptible to defeat by countervailing reasons. Because one is under no obligation to critically evaluate the strength of the non-inferential, epistemic support connecting an experience to a perceptual belief, entitlement must be understood as a primitive, weaker type of epistemic good. One has a prima facie entitlement to one's perceptual belief in the sense that countervailing reasons can serve as defeaters of that warrant.

A perceptual entitlement can be defeated in one of two ways. First, an entitlement can be undermined if one has reason to believe that one is in unfavorable viewing conditions, or that one's perceptual faculties are not working properly. For instance, if Peterson were to have evidence that her optic nerve had just been severed, she would no longer be entitled to her belief that her surrounding environment is dark. Secondly, entitlements can be overridden if one has independent evidence that the world is not the way one's experience presents it as being. Peterson has been told from a credible authority (or she has seen for herself on separate occasions) that the lines of the MüllerLyer illusion are equal in length, even though her current visual experience represents 
them as being different. Her visual experience affords her no entitlement to believe that one line is longer than the other. ${ }^{28}$

My suggestion, therefore, is that defeaters come from the reasons one has, that is, those that have gained membership in the space of reasons. Reasons can strip a perceptual belief of the epistemic support it receives from the corresponding experience. This is why Burge holds that in addition to being grounded by a reliably veridical experience, one is granted an entitlement to a perceptual belief only in the absence of undermining or overriding defeaters of the kind mentioned one paragraph above. It is in virtue of this 'absent reasons for doubt' clause for which I have been arguing that our reliance on experience in belief formation is a rational enterprise.

When an entitlement to a perceptual is defeated, is the subject no longer warranted in holding that belief? Not necessarily. When a perceptual belief is met with doubt, instigated by a third party (e.g. "You say that the tree is swaying, but how can you be so sure in this deep fog?") or the subject herself, the subject can counter the doubt by providing reasons. The moment reasons are offered as support, what was once a belief to which one had a perceptual entitlement now becomes a belief one is justified in holding. Such reasons might even include a conceptualization of the subject's own experience (e.g. "Granted it's foggy out, but the tree very clearly looks to be swaying."), but here it is a belief about the experience (with propositional structure), not the experience itself, which is providing the primary epistemic support. ${ }^{29}$

\footnotetext{
${ }^{28}$ For more on the distinction between undermining and overriding defeaters, see Pollock and Cruz (1999).

${ }^{29}$ Burge (2003), p. 529
} 
The purpose of this section has been to describe what I see as some of the key elements of entitlement and justification, and how they are to be distinguished. I have not tried to fashion any conclusive arguments that such a distinction does exist; doing so is a much more ambitious project. Instead, I claim that by demonstrating how a division of warrant into two subtypes can adequately solve the bootstrapping problem, we will have a strong motivation to welcome the concepts of entitlement and justification into our epistemology. It is this topic to which we now turn.

\section{Section III: A Proposed Solution to the Bootstrapping Problem}

Let us quickly review from Section I the kind of diagnosis of the bootstrapping problem we are ultimately seeking. B1 constitutes a piece of basic knowledge, which implies that Reggie's having perceptual knowledge does not presuppose that he already knows that perception is a reliable source. In addition, the track-record argument (B1-B5) Reggie utilizes fails to provide justification for B5. There must be something amiss at some point in the track-record argument.

I argue that the proposed division of warrant into the subtypes of entitlement and justification as described in Section II can account for why things go wrong for Reggie. As a start, we acknowledge that entitlement is an externalist type of warrant in the sense that one need not have reflective access to the features that make one's belief warranted. This implies that one need not know, or be warranted in thinking, that one's experiences are reliably accurate in order to have entitlements to one's perceptual beliefs. It is because our perceptual beliefs are warranted (when they are) in virtue of being entitled, that such beliefs can amount to basic knowledge. Thus, it is consistent with my view that 
Reggie's first-order belief that there is an $\mathrm{F} a$ ahead (B1) is warranted, since he has an entitlement to hold it. And, although I have not argued along these lines thus far, it is plausible that Reggie is also entitled to his belief about his own experience (B2). ${ }^{30}$

Justification, in contrast, is internalist in the sense that being justified implies that one is capable and willing to reflect on the reasons which inferentially ground the belief, to place them under self-scrutiny — that is, to evaluate one's own epistemic situation. In Reggie's case, if his second-order belief concerning the reliability of his experiences (B5) is warranted, it must be so in virtue of being justified. Accordingly, this is a belief over which he himself must take ownership. Given the heightened standards associated with justification, when Reggie comes to deliberate on the epistemic support favoring B5, as a rational agent he himself ought to recognize that has reasoned in a vicious circle toward this conclusion. This admission would constitute a compelling reason to doubt B5, which, I claim, thereby undermines any justification for this second-order belief.

Therefore, what we have in Reggie's situation is a failure of warrant-transmission occurring somewhere in the sequence starting with B1 and B2 and terminating with B5. ${ }^{31}$ What do I mean by this? One way of thinking of a warrant-transmission failure is such that if $\mathrm{S}$ knows that $p$ logically implies $q$ and $\mathrm{S}$ is warranted in believing $p$, then the warrant for S's belief that $p$ does not transmit to S's belief that $q$ if S cannot acquire a new warrant for believing $q$ based on deducing $q$ from $p$.

${ }^{30}$ See Burge (1996) on our putative entitlement to self-knowledge. Of course, I have not at all argued for the existence of entitlements to beliefs about our own mental states (see fn. 13). For the sake of this discussion, I will assume that the warrant for B2, however it is attained, is beyond dispute.

${ }^{31}$ In light of the proposed distinction between entitlement and justification described in Section II, I will now concentrate on warrant-transmission rather than justification-transmission. 
Now, it has been widely noted that cases of transmission failure need not be regarded as violations of closure. ${ }^{32}$ In light our proposed distinction between entitlement and justification described in Section II, let us turn away from CPJ and focus instead on the following emended closure principle:

(CPW) If $\mathrm{S}$ is warranted in believing that $p$, and $\mathrm{S}$ knows that $p$ logically implies $q$, and $\mathrm{S}$ deduces $q$ on the basis of $p$, then $\mathrm{S}$ is warranted in believing that $q$.

If we let HAND be the proposition that I have hands and EXT be the proposition that there is an external world, my being warranted in believing HAND implies (assuming CPW) that I am warranted in believing EXT. Some have denied that the warrant for HAND (which presumably is my experience of seeing my two hands) transmits to the warrant for EXT, for the reason that my experience as of hands can adequately warrant my belief that HAND only on the presupposition that I am already warranted in believing EXT. Thus, my warrant for EXT is epistemically prior to my warrant for HAND. Nonetheless, all of this is consistent with closure, for nothing mentioned in CPW states that the warrant for EXT must be sourced in one's deducing EXT from HAND. So long as the source of one's warrant for EXT is something independent of reasoning one's way from HAND to EXT, this instance of warrant-transmission failure need not be taken as a violation of $\mathrm{CPW} .{ }^{33}$ One might, then, attempt to apply this assessment of transmission failure to Reggie's own chain of reasoning. According to this suggestion, whether

\footnotetext{
${ }^{32}$ Cf. Silins (2005)

${ }^{33}$ One prominent advocate of this sort of move is Crispin Wright $(2003,2004)$, who holds that we have a non-evidential, unearned kind of warrant, called entitlement (where this is a type of warrant unrelated to the one we have thus far been discussing), to what he calls cornerstone propositions: propositions whose warrant is a precondition for the possibility of there being warrant for a vast range of other beliefs. Some cornerstone propositions Wright cites are, "There is a material world," "There are minds beside my own," and "The world did not come into being today replete with apparent traces of a more extended history." (2004, p. 170-71)
} 
Reggie's experiences can provide him with warrant for his corresponding perceptually based beliefs depends on whether he already has warrant for believing that his perceptual system is reliable. So, the reasoning he undergoes could not provide him with a new warrant for holding B5.

Although I agree with the suggestion being put forth that Reggie's bootstrapping procedure engenders a failure of warrant-transmission, there is an important reason why we must distance ourselves from the above-proposed assessment as to why transmission fails. Specifically, if we were to agree that an experience's providing warrant for a perceptual belief depends on one already having warrant for thinking that one's experiences are reliable, then we would have to deny that there could be any basic knowledge. As we saw in Section I, in order to avoid the over-intellectualization problem, we should allow that individuals can be warranted in their perceptual beliefs without us also demanding that they already be in possession of any relevant or collateral background knowledge. One can have perceptual knowledge of one's surroundings even if one knows nothing about the reliability of one's perceptual system. Thus, we must allow for the possibility of basic knowledge. That is why we are advised to seek some alternative to the assessment, described one paragraph above, of the warrant-transmission failure in Reggie's case. The reason why warrant fails to transmit, and moreover why bootstrapping is generally impermissible, cannot be that Reggie's being warranted in B5 is a precondition for his experiences conferring warrant for his B1-like beliefs. ${ }^{34}$ Rather,

\footnotetext{
${ }^{34}$ To be fair, Wright might object that his view does not preclude basic knowledge because the unearned warrants we have to cornerstone propositions - like the one expressed by B5 - are not warrants to believe those propositions. Rather, they are warrants to presume or to rationally trust that they are true, which does not imply that they are known (Wright 2004). In response, according to CPW, when one is warranted in believing that $p$, and one deduces $q$ from $p$, what one has a warrant to do is believe that $q$. If
} 
it is my suggestion that the warrant fails to transmit because were Reggie a responsible epistemic agent who carefully and methodically arrives at his own judgments, it should have been of his own admission that this argument gives him inadequate reason to believe that his perceptual system is reliable.

If the track-record argument engenders a failure of warrant-transmission, at what stage of the argument does the failure occur? Jesper Kallestrup (2009) has argued that the failure occurs, in connection to Reggie's argument, at the inference from B1 and B2 to B3. According to Kallestrup, unless one already has warrant to believe that source G produced a true belief that $p$, one lacks warrant to believe $p$ when one has warrant to believe $\mathrm{G}$ produced the belief that $p$ but no warrant to believe $\mathrm{G}$ is reliable. ${ }^{35}$ Thus, given that Reggie has warrant for B2 but lacks warrant for B5, he can have warrant for B1 only if he already has warrant for B3. It is especially important to note that warrant for the belief that $\mathrm{G}$ produced a true belief that $p$ is necessary for having warrant to believe that $p$ only when one also has warrant to believe $\mathrm{G}$ produced the belief that $p$. The reason why the necessary condition applies only in these specific circumstances, Kallestrup argues, is that when one has warrant to believe $\mathrm{G}$ produced the belief that $p$, one reflectively relies on $\mathrm{G}$ as a source of belief; in these sorts of circumstances, the question about the epistemic credentials of $\mathrm{G}$ arises. ${ }^{36}$ Given that $\mathrm{G}$ itself is now the object of one's reflection, it would be irresponsible for one to then rely on $\mathrm{G}$ in the absence of any warrant for thinking that $\mathrm{G}$ is reliable.

\footnotetext{
Wright is unwilling to deny a principle like CPW, then it seems the cornerstone propositions to which we have these unearned warrants must not merely be trusted, but believed as well. Thanks to [...] for making this point clear to me.

35 Kallestrup (2009), p. 165-66. As a terminological point it should be noted that Kallestrup uses "justification" instead of "warrant."

${ }^{36}$ Kallestrup (2009), p. 168
} 
In my opinion Kallestrup rightly pinpoints the place in track-record arguments where warrant fails to transmit, and his explanation for why such failures occur is laudable. But Kallestrup's aim is to defend reliabilism against the bootstrapping problem; the viewpoint he adopts, I argue, ultimately loses sight of the reliabilist project in general. There are two reasons why I think this is so. First, Kallestrup holds that gaining warrant for the belief that $p$ is more demanding when one also has warrant for believing that it was produced by a given source, and one also lacks warrant for believing that that source is reliable, than when one doesn't. I do not dispute the claim being made here, but from a reliabilist point of view, traditionally reliabilists have held that a belief's being produced by a reliable source is by itself sufficient for warrant. A reliabilist might not want to impose varying standards for warrant that go beyond the reliability or truth-ratio of a belief-forming process. Secondly, Kallestrup claims that it would be epistemically irresponsible for the subject to reflectively rely on a belief source for which one has no warrant to believe in its reliability. But, such deontological considerations as to whether a subject's belief is responsibly held are traditionally confined to internalist theories in epistemology, and reliabilism is paradigmatically an externalist theory.

These two concerns are not meant to serve as outright objections to Kallestrup's reliabilist defense. Reliabilism comes in many versions; one may be content to admit that it imposes varying standards and welcomes deontological judgments. ${ }^{37}$ Nevertheless, I believe that partitioning warrant into entitlement and justification as I have proposed provides an account of warrant-transmission failure that is congruent with Kallestrup's

\footnotetext{
${ }^{37}$ On this point see Kallestrup's (2009) fn. 22.
} 
proposal. If I am correct, then we have a way of explaining the inadequacies of bootstrapping without jumping onto a (at the very least) questionable reliabilist view.

On my account Reggie's reasoning exemplifies a case in which a set of beliefs to which he has entitlements (B1 and B2) fails to transmit their warrant to a belief he is justified (or would be justified, were he warranted) in holding (B3). Let me be clear that this kind of warrant-transmission failure should be confined to a restricted range of situations. For, it must be acknowledged that in general, it is perfectly acceptable to acquire a new justification for an inferential belief on the basis of a non-inferential belief to which one is entitled. Supposing that I have an entitlement to my perceptual belief that there is darkness all around, when I infer that all the lights are off, I have acquired a new justification for the latter belief at the moment I make the inference. Similarly, based on my perceptual belief that the man over there has white hair and a wrinkled face, I would be justified in concluding that that man was alive during the Kennedy Administration. Both of these examples demonstrate cases in which warrant transmits: the beliefs to which I have entitlements deliver adequate epistemic support to the beliefs I have inferred on their basis (in the form of justifications).

There must be something that distinguishes those situations in which entitlements successfully transmit their warrant onto justifications—as in the two examples above - from those in which they fail to do so - as in a bootstrapping situation. Although I will not attempt to provide a principled explanation that answers this question, I claim that part of the answer has to do with what is reasonably expected of the subject to consider when she engages in self-reflective deliberations. When I infer that all the lights are off on the basis of my belief that there is darkness all around, whether the inferred 
belief is justified does depend in part on the fact that my perceptual system is reliable.

(To be more specific, the justification for the inferred belief is a perceptual belief whose warrant is grounded in an experience. If my perceptual system were unreliable, its productive experience would not warrant the corresponding perceptual belief, which in turn would prevent that perceptual belief from justifying the inferred belief.) But it does not depend on my own judging that it is reliable. For, although a belief that the lights are off is epistemically rooted in one's experience, it is not a belief about that experience. To be sure, there are considerations that as a justified agent I must be willing to reflect upon in regards to the lights' being off. But, that which I am required to consider in this case is whether its being dark (where I am already entitled to take the corresponding experience at face value) is indeed a good reason to believe that all the lights are off. (It may be incumbent upon me, for instance, to consider whether the darkness of the environment is compatible with some dim light in the corner of the room—occluded by a couch or other large object—being illuminated.) In most typical circumstances, this is a question I am able to answer without considering whether my vision is in tact. ${ }^{38}$

In Reggie's case, in contrast, the belief he deduces on the basis of B1 and B2 (i.e. B3) makes reference to his own experience. In order for B3 to be a justified belief, that which the belief is about suddenly becomes an object of scrutiny. Whereas my belief that the lights are off is a belief about the lights in the room, B3 is about the accuracy of Reggie's own experience. It is therefore reasonable to expect that part of Reggie's deliberations in favor or against B3 center on the strength of his perceptual faculties. It is correct that B3

\footnotetext{
38 To be sure, there may be circumstances wherein it is appropriate or even obligatory to reflect on the accuracy of one's experiences. In cases such as these, one might come to doubt that they are accurate, in which case the justification for one's belief, say, that the lights are off is defeated. It is important for us to recognize, however, that these will only be extraneous, abnormal circumstances.
} 
is logically entailed by B1 and B2, but there are situations in which relying on a logically valid or sound argument is not enough to gain epistemic justification for believing the conclusion. This, I think, is one of the key lessons the bootstrapping problem teaches us philosophers; track-record arguments on their own are logically sound, yet most of us are just unwilling to attribute justification to those who draw their conclusions. My claim is that given the specific content associated with B3, in this context Reggie should have pause for carrying out the inference from B1 and B2 to B3. Unlike a fully reliabilist account of justification, the account of justification I described in Section II—one that gets explained in contrast to entitlement—does not preclude deontological evaluation of how one reasons. Given that the warrant for B3 comes in the form of a justification (or would come in that form, were it warranted), we are free to assess that Reggie is epistemically obligated to withhold forming B3 unless he has justification for thinking his perceptions are reliable indicators of the truth.

\section{Section IV: Entitlement, Justification, and Closure}

As one final thought, I would like to address how this solution to the bootstrapping problem relates to closure. As we already saw, it does not follow from the claim that there can be failures of warrant-transmission that closure is false. On my view, there can be failures of warrant-transmission when one's chain of reasoning takes one from a belief for which one has an entitlement to a belief one is justified (or would be justified, were one warranted) in holding. Nevertheless, one might still be worried that my position leads us to reject CPW. What is the basis for this worry? First note that because entitlement and justification are understood to be subtypes of the more general epistemic 
good, warrant, CPW comes in several varieties. One of these is CPJ. Nothing I have said in the previous section poses a challenge to CPJ. However, it may be thought I am committed to denying a different version of CPW, namely:

(CPE-J) If $\mathrm{S}$ is entitled to her belief that $p$, and $\mathrm{S}$ knows that $p$ logically implies $q$, and $\mathrm{S}$ deduces $q$ on the basis of $p$, then $\mathrm{S}$ is justified in believing that $q$.

The worry is that when the warrant for $p$ (in the form of an entitlement) fails to transmit to the warrant for $q$ (in the form of a justification), one would be unwarranted in believing that $q$ (on the basis of the deduction), yet one's entitlement to the belief that $p$ would remain intact. Hence, we would be forced to reject CPE-J. However, I think we need not accept this undesirable result. I argued that the reason why warrant does not transmit in cases of bootstrapping is that as one engages in self-reflective deliberation, and one comes to admit that one's reasoning is faulty, one acquires a reason to doubt what one has inferred. Reggie, for instance, may come to doubt that his experience is accurate, which amounts to an undermining defeater for his justification for B3. But as we saw in Section II, entitlement is a more primitive, weak type of epistemic good. One is prima facie entitled to rely on one's experience in belief formation only if there are no reasons to doubt what one believes. But if in Reggie's case he now has a reason to doubt $\mathrm{B} 3$, it is apparent that he thereby also has a reason to doubt B1 (assuming that the warrant for B2 is not up for dispute). So, although bootstrapping depicts an abnormal situation in which warrant fails to transmit, we need not identify this as a counterexample to CPE-J or, moreover, to CPW. We can accept that warrant is closed under known entailment, even when the entailment occurs between an entitlement and a justification. For, when warrant fails to transmit as in cases of bootstrapping, and the justification for one's 
inferred belief is undermined, the entitlement one has to one's perceptual belief is undermined as well.

Is this a skeptical outcome? Admittedly it is, for if what I have been arguing is correct, Reggie no longer has warrant, of any kind, for his perceptual belief. While there may be those who are unwilling to accept such an outcome, I believe that in some situations a skeptical point of view is the one most deserved; and Reggie's exemplifies such a situation. Let me explain. Suppose Reggie and little four-year-old Sally are sitting near one another, and they both have the same type of visual experience of an $\mathrm{F} a$. On the basis of their respective experiences, they each come to believe there is an F $a$ ahead. Reggie goes on to bootstrap his way B3, while Sally proceeds no further in her cognitive exercise than her B1-like belief. In a situation such as this, we get the seemingly odd result that Sally's belief is warranted, while Reggie's is not. But, why should this bother us? It is true (or so we shall assume) that Reggie and Sally's perceptual systems are equally reliable and that their experiences are both accurate. However, it is important for us to recognize that Reggie is now in a different epistemic situation with respect to his B1 than Sally is with respect to hers. Once he begins to bootstrap, he does not simply believe there's an F $a$ ahead; rather, he believes there's an $\mathrm{Fa}$ ahead qua reason to believe that his experience is accurate. Reggie, unlike Sally, has entered into the space of reasons; he is now using this belief as a premise in an argument. As I have said, that he comes to recognize that B3 is ill-supported—or should come to recognize were he being epistemically responsible $\smile$ constitutes a reason to doubt $\mathrm{B} 3$ and, by extension, B1. As Sally has brought no such argument upon herself, her perceptual entitlement to her B1 remains undefeated. 
Nothing concerning what I have said forces us to jump to a more global skepticism, such that once people like Reggie commence their bootstrapping they can never again acquire warrant for their perceptual beliefs. Let me close with two possible options for keeping skepticism confined to bootstrapping situations. First, we must not lose sight of the fact that the bootstrapper's situation is something well out of the ordinary: it is a situation wherein the subject has brought upon herself a demand to answer deeper, more perplexing, skeptical challenges. To even raise the question of whether one's experience is accurate is something that goes beyond the practices occurring within our more ordinary, run-of-the-mill epistemic contexts. The bootstrapper's situation is something much different from the one in which I see a bird flying above the water and consequently judge there to be one over there. Thus, I suggest that whereas in Reggie's context - the one in which he infers B3 from B1 and B2-his entitlement to B1 is undermined, we need not assume that a defeat of this kind, within this context, carries over to other contexts in which Reggie does not attempt to pull himself up by his own bootstraps. Perhaps after Reggie has moved on, and he has stopped meddling with ways of coming know of the accuracy of his perceptions, he regains entitlements to rely on his experiences.

As a second option, perhaps it is the case that after it has been defeated, Reggie can recover a warrant for B1, yet through alternative means. If, as I have been advocating throughout, the concept of entitlement has a legitimate place in epistemology, there may be other classes of beliefs to which we have entitlements. Burge (1993), for instance, has argued that we have prima facie entitlements to our various testimony-based beliefs. Suppose Reggie now doubts B1, prompted by his failed attempt to bootstrap his way to 
B3. He then turns to Sally and asks her, "Sally, do you see a red cube?" "Yes, there's one right ahead of us." If it is right that we have epistemic entitlements to trust the testimonies of others, this could be a way for Reggie to acquire a new, independent warrant for B1. And yet, this would be a kind of warrant that is not grounded in perception. To be sure, one would be unable to form a belief based on what another says without perception. Arguably, it is right that one's having an entitlement to a testimonybased belief presupposes that one's perceptual faculties are reliably accurate. But none of this implies that perception is itself a feature of the warrant one acquires by trusting the word of another. ${ }^{39}$ In comparison, though it may be necessary for one to utilize memory in order to be justified to draw a conclusion in a demonstrative proof (by way of remembering what the earlier premises stated) - and a lapse in memory can even be a source of error in one's reasoning — we need not think that memory is a part of the justification itself for believing the conclusion. Thus, it may be that Reggie can regain a warrant for B1, yet in a different form. As I say, these two options are meant merely as suggestions as to how we may be able to embrace the outcome of Reggie's bootstrapping situation, which I maintain is appropriately a skeptical one, while keeping a more global skepticism at bay. A fuller defense of either of these options must be set aside for future projects.

In conclusion, I have argued that a predominantly internalist response to the bootstrapping problem is committed to an over-intellectualized epistemology, while a predominantly externalist response is committed to sanctioning bootstrapping as a benign procedure. Both of these outcomes are difficult to bear. As an alternative, I have

${ }^{39}$ Burge (1993), p. 466 
proposed a Burgean view that incorporates both externalist elements (in the form of entitlements) and internalist elements (in the form of justifications). This view has delivered a solution that both avoids over-intellectualization and prohibits bootstrapping. ${ }^{40}$

\section{References}

Alston, W. (1996). The Reliability of Sense Perception. Ithaca: Cornell University Press. Altschul, J. (Forthcoming). "Reliabilism and Brains in Vats." Acta Analytica. Audi, R. (1993). The Structure of Justification. Cambridge: Cambridge University Press. Bergmann, M. (2004). "Epistemic Circularity: Malignant and Benign." Philosophy and Phenomenological Research, 69, 709-27.

Bergmann, M. (2006). Justification Without Awareness. Oxford: Oxford University Press.

Bermudez, J. (2007). "What is at Stake in the Debate on Nonconceptual Content?" Philosophical Perspectives, 21, 55-72.

Bonjour, L. (1980). "Externalist Theories of Empirical Knowledge." Midwest Studies in Philosophy, 5, 53-73.

Brueckner, A. (2008). "Experiential Justification.” Epistemology, 17. Oxford Scholarship Online Monographs, 105-121.

Brewer, B. (1999). Perception and Reason. Oxford: Oxford University Press.

Burge, T. (1977). "Belief De Re." The Journal of Philosophy, 74, 338-362.

Burge, T. (1993). "Content Preservation.” The Philosophical Review, 102(4), 457-488.

Burge. T. (1996). "Our Entitlement to Self-Knowledge." Proceedings of the Aristotelian Society, 96(1), 91-116.

Burge. T. (2003). "Perceptual Entitlement." Philosophy and Phenomenological Research, 67(3), 503-548.

Burge, T. (2005). "Disjunctivism and Perceptual Psychology." Philosophical Topics, $33(1), 1-78$.

Burge, T. (2007). Foundations of Mind. Oxford: Oxford University Press (2007).

Cohen, S. (2002). "Basic Knowledge and the Problem of Easy Knowledge." Philosophy and Phenomenlogical Research, 65(2), 309-329.

Conee, E. and Feldman, R. (2001). "Internalism Defended." in H. Kornblith (ed.) Epistemology: Internalism and Externalism. Oxford: Blackwell Publishers.

Davidson, D. (1986). "A Coherence Theory of Truth and Knowledge." in E. Lepore (ed.) Truth and Interpretation: Perspectives on the Philosophy of Donald Davidson. Oxford: Blackwell Publishing.

Evans, G. (1982). The Varieties of Reference. Oxford: Oxford University Press.

${ }^{40}$ Acknowledgments 
Fumerton, R. (1995). Metaepistemology and Skepticism. Lanham: Rowman \& Littlefield. Goldman, A. (1979). "What is Justified Belief?" in G. Pappas (ed.) Justification and Knowledge. Dordrecht: Reidel Publishing.

Goldman, A. (1986). Epistemology and Cognition. Cambridge, MA: Harvard University Press.

Heck, R. (2000). "Non-conceptual Content and the 'Space of Reasons'." The Philosophical Review, 109(4), 483-523.

Heck, R. (2007). "Are There Different Kinds of Content?" in B. McLaughlin and J. Cohen (eds.), Contemporary Debates in Philosophy of Mind. Oxford: Blackwell Publishing.

Kallestrup, J. (2009). "Reliabilist Justification: Basic, Easy, and Brute." Acta Analytica, $24,155-171$.

Majors, B. and Sawyer, S. (2005). "The Epistemological Argument for Content Externalism." Philosophical Perspectives, 19, 257-280.

McDowell, J. (1994). Mind and World. Cambridge, MA: Harvard University Press.

Peacocke, C. (1992). A Study of Concepts. Cambridge, MA: MIT Press.

Peacocke, C. (2004). The Realm of Reason. Oxford: Oxford University Press.

Plantinga, A. (1993). Warrant and Proper Function. Oxford: Oxford University Press.

Pollock, J. and Cruz, J. (1999). Contemporary Theories of Knowledge (2 ${ }^{\text {nd }}$ Edition). New Jersey: Rowman \& Littlefield.

Pritchard, D. (Forthcoming). "Evidentialism, Internalism, Disjunctivism." in T. Dougherty (ed.), Evidentialism and its Discontents. Oxford: Oxford University Press.

Pryor, J. (2000). "The Skeptic and the Dogmatist." Nous, 34, 517-49.

Pryor, J. (2005). "There is Immediate Justification." in M. Steup and E. Sosa (eds.), Contemporary Debates in Epistemology. Oxford: Blackwell Publishing.

Roskies, A. (2008). “A New Argument for Nonconceptual Content." Philosophy and Phenomenological Research, 76(3), 633-659.

Sellars, W. (1963). "Empiricism and the Philosophy of Mind." in Science, Perception and Reality. London: Routledge \& Kegan Paul.

Silins, N. (2005). “Transmission Failure Failure.” Philosophical Studies, 126, 71-102.

Van Cleve, J. (2003). "Is Knowledge Easy or Impossible? Externalism as the Only Answer to Skepticism." in S. Luper (ed.), The Skeptics. Ashgate, Aldershot.

Vogel, J. (2000). “Reliabilism Leveled.” The Journal of Philosophy, 97(11), 602-623.

Vogel, J. (2008). "Epistemic Bootstrapping.” The Journal of Philosophy, 105(9), 518539.

Wright, C. (2003). "Some Reflections on the Acquisition of Warrant by Inference." in S. Nuccetelli (ed.), New Essays on Semantic Externalism, Skepticism and SelfKnowledge. Cambridge, MA: MIT Press.

Wright, C. (2004). "Warrant for Nothing (and Foundations for Free)?" Aristotelian Society Supplementary Volume, 78(1), 167-212.

Zalabardo. (2005). "Externalism, Skepticism, and the Problem of Easy Knowledge." The Philosophical Review, 114(1), 33-61. 